\section{A rapid capillary test for out-patient anticoagulant therapy}

\section{POLLER From the Haematology Department, Withington Hospital, Manchester}

A capillary method is described for controlling outpatient anticoagulant therapy. The reagent can be easily prepared in routine laboratories.

\section{EQUIPMENT AND REAGENTS}

These are a water-bath at $37^{\circ} \mathrm{C}$., with a rack to contain $10 \times 70 \mathrm{~mm}$. test tubes, two pipettes, $0.05 \mathrm{ml}$. for the blood sample and $0.25 \mathrm{ml}$. for the reagent, ${ }^{1}$ a sterile lancet, and a stop watch.

\section{TEST REAGENT}

HUMAN BRAIN THROMBOPLASTIN This is the saline extract or the saline extract of acetone brain giving a normal prothrombin time of 10 to 13 seconds in the Quick test.

\section{CALCIUM CHLORIDE $\mathrm{M} / 40$}

ADSORBED HUMAN PLASMA Fresh normal citrated plasma is pooled or, if preferred, the fresh supernatant plasma specimens pooled from patients on anticoagulant therapy. The pooled plasma is then treated as follows:-

Fresh plasma obtained in a clean vessel was processed through a sterile Seitz filter using Carlson ${ }^{2}$ EK sterilizing asbestos filtering films. Not more than $16 \mathrm{ml}$. of plasma should be filtered through a $3 \mathrm{~cm}$. disc and not more than $30 \mathrm{ml}$. through a $6 \mathrm{~cm}$. disc. Adsorbed plasma was collected in a clean $6 \times \frac{5}{8}$ in. test tube, inserted into a flask, transferred to a sterile, clean $1 \mathrm{oz}$. bottle and stored in a deep freeze cabinet. The resulting plasma should be free of prothrombin.

\section{METHOD}

Equal volumes of human brain thromboplastin, adsorbed plasma, and $M / 40$ calcium are mixed. The mixture is then decanted into small volumes and stored in a deep freeze cabinet. Warmed reagent is decanted in $0.25 \mathrm{ml}$. volumes into the test tubes in the water-bath. A sharp lancet is used to prick the finger to ensure a rapid flow of blood. The blood is collected to the $0.05 \mathrm{ml}$. mark, blown into the reagent, and the stop watch started. The resulting clotting time is recorded in seconds. The results may be expressed as percentages from reference to a dilution curve performed by diluting normal pooled plasma from

${ }^{1}$ Made by Elliott's Ltd. for the Thrombotest technique.

2Obtained from John C. Carlson Ltd., Ashton-u-Lyne, Lancs.

Received for publication 13 July 1962. six subjects with the adsorbed plasma described above. The results are plotted on double logarithm graph paper. Alternatively, a prothrombin ratio can be employed which obviates the necessity for the dilution curve. Normal results lie between 21 and 25 seconds with our own batch of thromboplastin reagent.

\section{THERAPEUTIC RANGE}

The therapeutic range is lower in percentage activity than with the Quick test because excess adsorbed plasma is present. Using the dilution curve described above it appears to be between 6 and $20 \%$ with an optimum of 8 to $15 \%$. The ratio represented by test result/control result is approximately equivalent to twice to three and a half times the control. The therapeutic range was originally devised from parallel observations with other techniques. It has been subsequently confirmed in clinical practice.

\section{Modification of an extraction technique for estimation of Evans blue in plasma}

\section{MICHAEL HOBSLEY and JOAN THURN From the Department of Surgical Studies, Middlesex Hospital, London}

Four years ago a publication from this laboratory described an extraction technique for the estimation of Evans blue in plasma (Hobsley and Dew, 1958). One year ago, this method in our hands stopped giving accurate results. We believe that the reason for this change was that the commercial preparation of cellulose tissue that we originally used was modified by the manufacturers at that time.

We have since found that acceptable results can be obtained if Andrex white toilet tissue is substituted for the preparation that we originally used. Three sheets of Andrex, each $14 \times 11.5 \mathrm{~cm}$., are pulped with $30 \mathrm{ml}$. $0.9 \mathrm{~g} . / 100 \mathrm{ml}$., sodium chloride solution. The results of 18 estimations of a plasma sample carried out by two different observers gave a standard deviation of $2.78 \%$. The extraction rate averaged $99 \%$ compared with a standard aqueous solution, whether the latter was treated identically, or read directly in the spectrophotometer without having been passed through the extraction procedure. These results compared favourably with those we described in our original paper.

\section{REFERENCE}

Hobsley, M., and Dew, E. D. (1958). J. clin. Path., 11, 451.

Received for publication 16 June 1962. 